\title{
Role of bundled intervention in reducing surgical site infection rate in gynecologic surgeries
}

\author{
Nisha Singh $^{1}$, Shweta Rai ${ }^{1}$, Shuchi Agrawal ${ }^{1 *}$, Gopa Bannerjee ${ }^{2}$, Renu Singh ${ }^{1}$ \\ ${ }^{1}$ Department of Obstetrics and Gynecology, King George's Medical University, Lucknow, Uttar Pradesh, India \\ ${ }^{2}$ Department of Microbiology, King Georges Medical University, Lucknow, Uttar Pradesh, India
}

Received: 17 December 2019

Revised: 16 January 2020

Accepted: 24 January 2020

*Correspondence:

Dr. Shuchi Agrawal,

E-mail: obgexpert@gmail.com

Copyright: $(\subset$ the author(s), publisher and licensee Medip Academy. This is an open-access article distributed under the terms of the Creative Commons Attribution Non-Commercial License, which permits unrestricted non-commercial use, distribution, and reproduction in any medium, provided the original work is properly cited.

\section{ABSTRACT}

Background: Surgical site infection (SSI) is most common nosocomial infection (15\%) among surgical patient's and contributes significantly to morbidity and mortality. CDC (2015) provides "bundled intervention for prevention of SSI. The present study was planned to evaluate the feasibility and usefulness of these bundled intervention in reducing SSI in our setup. Objectives of this study to study the effect of bundled interventions on SSI in gynaecologic surgery.

Methods: A total 50 cases undergoing gynecological surgery in elective OT included in pilot group and bundled intervention followed these pilot group cases compared with 50 control group operated in same OT in which bundled intervention not followed outcome measures recorded were Incidence of SSI, type of SSI, need for antibiotic usage, need for secondary suturing, duration of hospital stay.

Results: Out of 50 subjects in pilot group, five developed signs and symptoms of SSI giving an SSI rate of $10 \%$. Out of those five, two had superficial SSI and three had deep SSI, none of the patient had organ space SSI.SSI rate in 50 cases operated in the same operating room during the same time period without use of bundled interventions (control group) was $12 \%$.

Conclusions: Bundled approach is easy and feasible in all setups. It adds only three extra minutes to the total duration of the surgery with risk reduction of SSI.

Keywords: Bundled intervention, Prevention of surgical site infection, Risk factors of surgical site infection, Role, Surgical site infection

\section{INTRODUCTION}

Infection at or near surgical incisions within 30 days of an operative procedure is known as surgical site infection (SSI). ${ }^{1} \mathrm{SSI}$ is the most common nosocomial infection among surgical patients, accounts for $15 \%$ of all infections and contributes significantly to surgical morbidity and mortality. SSI has various risk factors. Current smokers are at a $30 \%$ increased risk of SSI and smoking cessation reduces $\mathrm{SS}^{2}$ Body mass index and obesity have also been linked to increased risk of SSI with studies showing wound complication rates in some procedures arising from $7 \%$ to $23 \%$ due to obesity. ${ }^{2,3}$ Depth of subcutaneous fat has been shown to be a strong risk factor and useful predictor for SSI. ${ }^{4}$ Other factors include anemia and diabetes mellitus. Duration of surgery has been identified as an important factor affecting SSI by the American Society of Anaesthesiologists (ASA). ${ }^{5}$ Vertical incision increases the risk of infection and suprafascial wound separation by an odds ratio of 10.7 when compared with pfannenstiel incision. ${ }^{6,7}$

SSI leads to increased duration of hospital stay, increased cost and higher rates of hospital readmission. CDC 
(2015) has provided guidelines for prevention of surgical site infection. These interventions are termed as "bundled intervention" which were effective in reducing SSI from $6 \%$ to $1.1 \%$.

In most Indian setups including ours, the CDC guidelines are not completely adhered due to various reasons. The present study was therefore planned to evaluate the feasibility and usefulness of these bundled intervention in reducing SSI in gynaecological surgeries performed in this setup.

\section{Objectives of this study were}

- To study the effect of "bundled interventions" on SSI in gynecologic surgery.

- To compare the SSI characteristics of the study group with cases undergoing routine surgical care.

\section{METHODS}

It was an interventional pilot study conducted in department of obstetrics and gynecology, King Georges Medical University, Lucknow. 50 women undergoing gynecology surgery through abdominal route in elective OT were recruited. Women undergoing surgery by vaginal route, laparoscopy and patients not willing to participate were excluded from the study.

After written informed consent, detailed history was taken and examination done for recording infection related risk factors. Bundled interventions were implemented as follows:

- Preoperative care included soap bath on morning of surgery, no hair removal and single shot ceftriaxone 2 gm intravenously 30 minutes before incision.

- Per-operatively, abdomen was cleaned with savlon, dried and then painted with povidone iodine that was left in place for 2 minutes. Surgeons and Nursing staff wore two pairs of gloves. Closure of rectus sheath was done with continuous suturing using vicryl no. 1 .

- After closure of rectus sheath; surgeon, assistants and nursing staff removed outer gloves. Abdominal wound was washed with $50 \mathrm{cc}$ normal saline. A new sterile cut sheet was put over the incision site. Closure of subcutaneous fat using chromic catgut 2-0 was done if subcutaneous fat thickness was $>2.5 \mathrm{~cm}$ by continuous suturing. Skin closure was done with nylon 1-0 by mattress sutures. Ceftriaxone $(2 \mathrm{~g})$ was repeated if surgery was prolonged for 4 hours or more. Post-operatively Inj. Ceftriaxone $1 \mathrm{gm}$ and Inj. Gentamycin $80 \mathrm{mg}$ IV 12 hourly for 24 hours. In case of presence of any risk factors, it was continued for 48 hours.

- Dressing was changed after 48 hours Suture removal was done on day 7 for pfannenstiel incision and day 9 for vertical incision.
Signs and symptoms of SSI as wound site pain, redness, discharge and fever were recorded. Other outcome measures of pilot and control group were: incidence of SSI, Microorganisms causing SSI, type of SSI, antibiotic usage for SSI, secondary suturing and duration of hospital stay.

\section{Statistical analysis}

The statistical analysis was done using SPSS19 the values were represented in number (\%) and Mean \pm SD. Chi square test used and $\mathrm{p}$ value calculated.

\section{RESULTS}

In present study the mean age of women in pilot group was 43.2 years and in routine care group 41.04 years which was comparable. Most common indication for surgery in pilot group for Benign indication in 32 cases for Malignancy in 18 cases versus 39 cases in routine care group done for benign indication and 11 cases done for Malignant indication. There was no risk factor like anaemia, diabetes, obesity, for SSI in 52\% cases in which bundeled intervention were followed and no risk factors in $64 \%$ patients of control group in which routine care was followed. Anaemia was the most common risk factors in both pilot group and routine care group. Table 1 shows that there was no statistically significant difference in number of risk factors for SSI among pilot group and routine care group.

Table 1: Number of cases with risk factor and without risk factors in two groups.

\begin{tabular}{|ll|l|}
\hline Risk factors & $\begin{array}{l}\text { Pilot group } \\
(\mathbf{n}=\mathbf{5 0})\end{array}$ & $\begin{array}{l}\text { Routine care } \\
\text { group }(\mathbf{n}=\mathbf{5 0})\end{array}$ \\
\hline With risk factors & 26 & 32 \\
\hline Without risk factors & 24 & 18 \\
\hline
\end{tabular}

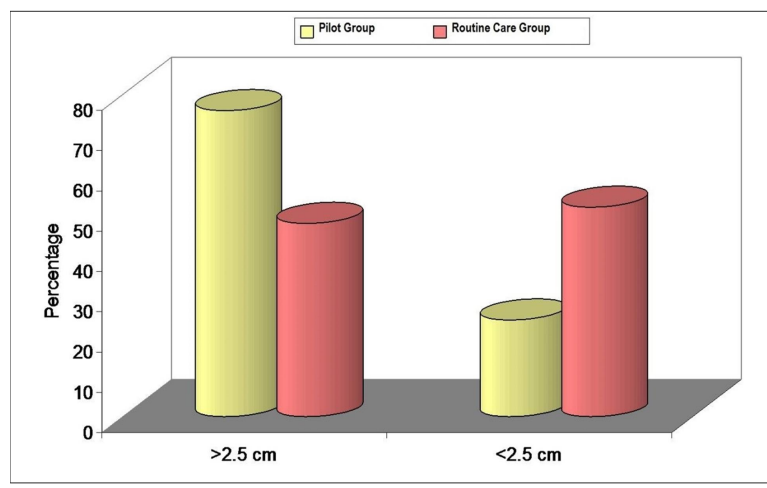

Figure 1: Correlation of subcutaneous fat thickness in pilot group and in control group.

Vertical incision was performed in majority of pilot Group in 37 cases $(74 \%)$ and in 34 cases $(68 \%)$ of routine care group. Size of incision in pilot group and routine care group ranged from $10-20 \mathrm{~cm}$ and 9 to $18 \mathrm{~cm}$ 
respectively with a mean of 14.38 and 13.88 respectively showing no statistically significant difference $(\mathrm{p}=0.287)$.

Table 2 shows practice of some preventive measures for SSI like pre-op bath, vaginal cleaning and avoiding hair removal was undertaken in significantly higher no of patients in pilot group. Preop antibiotic and part preparation protocol were exactly same in both the groups.

In present study subcutaneous fat thickness $>2.5 \mathrm{~cm}$ was significantly higher $(\mathrm{p}=0.004)$ in pilot group in 38 cases $(76 \%)$ as compared to control group in 24 cases (48\%) as shown in Figure 1.

Table 2: Preventive measures implemented for reducing SSI.

\begin{tabular}{|l|llll|ll|}
\hline \multirow{2}{*}{ Variables } & \multicolumn{2}{l}{ Pilot group $(\mathbf{n}=\mathbf{5 0})$} & \multicolumn{3}{l|}{ Routine care group $(\mathbf{n}=\mathbf{5 0})$} & \multicolumn{2}{l|}{ Statistical significance } \\
\cline { 2 - 8 } & No. & $\mathbf{\%}$ & No. & $\mathbf{\%}$ & $\chi^{\mathbf{2}}$ & 'p' \\
\hline Pre-op bath & 48 & 96.00 & 42 & 84.00 & 4.000 & 0.046 \\
\hline Vagina cleaning & 50 & 100.00 & 40 & 80.00 & 41.111 & 0.001 \\
\hline Avoiding hair removal & 46 & 92.00 & 50 & 100.00 & - & 0.041 \\
\hline Pre-op antibiotics & 50 & 100.00 & 50 & 100.00 & - & - \\
\hline Part preparation & 50 & 100.00 & 50 & 100.00 & - & - \\
\hline
\end{tabular}

Table 3: Rate and type of SSI.

\begin{tabular}{|lllllllll|}
\hline \multirow{2}{*}{ Type of SSI } & \multicolumn{2}{l}{ Pilot group $(\mathbf{n}=\mathbf{5})$} & \multicolumn{2}{l}{ Routine care group $(\mathbf{n}=\mathbf{6})$} & \multicolumn{2}{l|}{ Total $(\mathbf{n}=\mathbf{1 1})$} & \multicolumn{3}{l|}{ Statistical significance } \\
\hline & No. & $\mathbf{\%}$ & No. & $\mathbf{\%}$ & No. & $\mathbf{\%}$ & $\chi^{\mathbf{2}}$ & P \\
\hline Superficial SSI & 2 & 40.00 & 4 & 66.67 & 6 & 54.54 & 0.782 & 0.376 \\
\hline Deep SSI & 3 & 60.00 & 2 & 33.33 & 5 & 45.45 & 0.782 & 0.376 \\
\hline Organ SSI & 0 & 0.00 & 0 & 0.00 & 0 & 0.00 & - & - \\
\hline
\end{tabular}
$\chi^{2}=0.782,(\mathrm{df}=1) ; \mathrm{p}=0.376$

Table 4: Correlation of type of surgery and SSI.

\begin{tabular}{|c|c|c|c|c|c|c|c|c|}
\hline \multirow[t]{2}{*}{ Type of surgery } & \multicolumn{2}{|c|}{$\begin{array}{l}\text { Pilot group } \\
(\mathbf{n}=\mathbf{5})\end{array}$} & \multicolumn{2}{|c|}{$\begin{array}{l}\text { Routine care group } \\
(\mathrm{n}=6)\end{array}$} & \multicolumn{2}{|c|}{ Total $(n=11)$} & \multicolumn{2}{|c|}{$\begin{array}{l}\text { Statistical } \\
\text { significance }\end{array}$} \\
\hline & No. & $\%$ & No. & $\%$ & No. & $\%$ & $\chi^{2}$ & $\mathbf{P}$ \\
\hline Panhysterectomy & 2 & 40.00 & 2 & 33.33 & 4 & 36.36 & 0.052 & 0.819 \\
\hline Type II radical hysterectomy & 2 & 40.00 & 1 & 16.67 & 3 & 27.27 & 0.749 & 0.387 \\
\hline $\begin{array}{l}\text { Panhysterectomy with } \\
\text { peritoneal/ omental biopsy }\end{array}$ & 1 & 20.00 & 1 & 16.67 & 2 & 18.18 & 0.020 & 0.887 \\
\hline TAH & 0 & 0.00 & 2 & 33.33 & 2 & 18.18 & 2.933 & 0.087 \\
\hline
\end{tabular}

$\chi^{2}=2.261(\mathrm{df}=3) ; \mathrm{p}=0.520$.

Table 5: Comparison of treatment of SSI cases.

\begin{tabular}{|l|lllll|l|}
\hline \multirow{2}{*}{ Treatment } & \multicolumn{7}{l}{ Pilot group $(\mathbf{n}=\mathbf{5})$} & \multicolumn{2}{l|}{ Routine care group $(\mathbf{n}=\mathbf{6})$} & $\mathbf{\%}$ & $\boldsymbol{\chi}^{\mathbf{2}}$ & P \\
\hline I.V. antibiotics & No. & $\mathbf{0}$ & No. & 100.00 & 2.933 & 0.087 \\
\hline Dressing & 3 & 60.00 & 6 & 100.00 & - & - \\
\hline Re-suturing & 5 & 100.00 & 6 & 33.33 & 0.782 & 0.376 \\
\hline
\end{tabular}

Majority of cases of pilot group (98\%) received antibiotics for 24-48 hours. Mean duration of antibiotic therapy in pilot group was 1.64 days while majority of routine care group cases received IV antibiotic for 3-5 days, $8.7 \%$ cases of routine care group received antibiotic even for 7 days. Duration of antibiotic drug therapy among women of pilot group (1.64 \pm 0.94 days) was found to be significantly lower than that of routine care group $(4.56 \pm 1.37$ days $)(\mathrm{p}<0.001)$.
In present majority of pilot group cases (98.00\%) received double antibiotics (Ceftriaxone + Gentamycine) while majority of routine care cases $(92.00 \%)$ received triple antibiotics (Ceftriaxone + Gentamycine along with Metrogyl). The amount of antibiotic usage was significantly more $(p<0.001)$ in routine care group.

Primary dressing was changed on $3^{\text {rd }}$ day in 49 cases $(98 \%)$ of pilot group and dressing was changed at or 
beyond 72 hours in majority of routine care group cases. Difference in timing of change of dressing was found to be statistically significant $(\mathrm{p}<0.001)$.

Table 3 shows out of 50 cases of pilot group, 5 developed SSI giving SSI rate of $10 \%$ while out of 50 cases of routine care group, 6 cases developed SSI giving SSI rate of $12 \%$. None of the cases of pilot group had organs space SSI, while 2 of them had superficial SSI and three of them had deep SSI.

In this study proportional difference was found in incidence of SSI among pilot and routine care group in various age group but this difference was not found to be statistically significant $(p=0.514)$. None of the patient of pilot group was given oral antibiotic. Oral antibiotic therapy lasted for 3 days among $24.00 \%$, for 5 days among $34.00 \%$ and 7 days among $42.00 \%$ patients in routine care group. SSI developed in 5 cases $(10 \%)$ in pilot group as compared to 6 cases $(12 \%)$ in routine care group, the difference not being statistically significant. Common SSI feature were induration and discharge, none of the patient had organ space SSI. The comparison of clinical features like fever, induration and discharge in bundeled intervention group and in routine care group did not show any significant difference and presence of risk factors like anaemia and diabetes among SSI cases of pilot among the patients suffering from SSI majority of patients of both groups, pilot versus routine care group were given vertical incision $(80 \%$ and $83 \%)$ Table 4 shows difference in type of surgery among patients with SSI of pilot group and routine care group was not found to be statistically significant $(\mathrm{p}=0.558)$.

Table 5 shows the treatment of SSI cases in the two groups. None of the patients was administered oral antibiotics while dressing was done in all the patients of both groups. IV antibiotics was used in higher proportion of subjects of routine care group $(100 \%)$ as compared to pilot group $(60 \%)$ but this difference was not found to be statistically significant $(\mathrm{p}=0.087)$ resuturing was required in higher proportion of patients of pilot group (60\%) compared to routine care group $(33.33 \%)$ but this difference was not found to be statistically significant.

\section{DISCUSSION}

SSI impose severe demands on healthcare systems at a time when resources are particularly constrained. CDC has provided criteria for identifying and preventing various types of SSI. However, in most hospital setups including ours, these criteria are not adhered to in totality. There is a lot of variation in type and duration of antibiotic used by operating surgeons of the same department. On review of literature on SSI, a new surgical technique by Johnson MP et al, was found known as "bundled intervention". 8 This technique adds an average of 3 minutes to the total surgery duration. It is an easy and feasible technique that can be easily incorporated in all abdominal gynecological surgeries.
The incidence of SSI was $10 \%$ in this pilot study and $12 \%$ in the routine care group. This incidence is comparable to the SSI incidence in studies done by Anderson DJ et al and Lake AG et al, which quote incidence of $6-11 \%$. $^{9,10}$

In present study anemia and diabetes were the risk factors among cases that developed SSI both in pilot and comparison group. Anaemia (30\%) and intraoperative/immediate post op blood transfusion (22\%) were the most common risk factors for SSI in the pilot study group. Young $\mathrm{H}$ et al, in their study found blood transfusion (pre, intra and post op) to be associated with all SSI after abdominal hysterectomy. ${ }^{11}$ Lake et al in their large multicenter analysis found no association between preoperative transfusion and SSI. ${ }^{10}$ Although intraoperative transfusion was identified to be associated with cellulitis and deep/ organ space SSI, but after adjusting for other variables in their study no statistically significant association between intraoperative blood transfusion and SSI was seen.

In present study subcutaneous tissue depth above $2.5 \mathrm{~cm}$ was significantly more common (76\%) in the pilot Group $(p=0.004)$ as compared to the routine care group $(48 \%)$. Despite this difference, the SSI rate was comparable in both the groups. Thus, increased SC thickness does not seem to increase SSI rate in the present study. Chelmow et al and Naumann et al, showed that for patients with subcutaneous tissue depth above $2 \mathrm{~cm}$, closure of dead space reduces wound separation and seroma formation. $^{12,13}$

In present study all components of preop preparation for prevention of SSI were undertaken in almost all cases of pilot group. The implementation of these preventive measures as preop bath, vaginal cleaning, Hair clipping was significantly higher in pilot group $(\mathrm{p}=0.046, \mathrm{p}=$ $0.001, p=0.04)$ than in routine care group. This shows the non-adherence to $\mathrm{CDC}$ guidelines in routine preoperative care. This result is in concordance with study by Eason $\mathrm{E}$ et al, showed that decreasing overall bacterial counts in the vagina has been proven to reduce the risk of SSI in gynecological surgeries. ${ }^{14}$ Cochrane analysis shows a greater risk of SSI with hair shaving than with hair clipping was found. ${ }^{15}$ In present study Ceftriaxone was the pre-op antibiotic used in both the pilot group and routine care group. A large retrospective multicentric cohort study by Uppal $\mathrm{S}$ et al, found beta lactams preferable to non-beta lactams combinations in SSI prevention for women undergoing hysterectomy. ${ }^{16}$ Vicas $\mathrm{P}$ et al, found no significant association between type of prophylactic antibiotic administered and risk of SSI. ${ }^{17}$

In present study majority (98\%) of women in pilot group received ceftriaxone and gentamycin post operatively, whereas in routine group, majority (92\%) of women received Ceftriaxone+Metrogyl+Gentamycin. Similar SSI rates in the pilot group and routine care group with higher antibiotic usage in the latter clearly indicate the benefit of 
bundled interventions. During this study a significant difference $(p<0.01)$ was observed in duration of antibiotic usage between pilot group and routine care group. Such antibiotics uses increases huge cost burden to the health care system without any extra advantage in SSI reduction. The present study clearly proves that CDC guidelines should be strictly adhered to even in tropical countries like India. With the use of these guidelines financial burden can be reduced with acceptable SSI rates.

In present in pilot group $98 \%$ of primary dressing was removed after 48 hours where as in routine care group $78 \%$ had primary dressing removal after 72 hours. Timing of change of primary dressing showed statistically significant difference in this study. With SSI rates comparable in the two groups, it seems reasonable to change dressing at 48 hours as per CDC guidelines. The surgical dressing was once thought to prevent SSI by protecting surgical wound from outside bacterial contamination until initial epithelialization. However, a large systematic review in 2012 suggested that SSI rates did not differ between those who did and did not receive surgical dressing. A 2014 Cochrane review failed to find evidence that surgical dressing reduces SSI risk. Similarly, a 2015 Cochrane review found that removal of surgical dressings within first 48 hours did not increase SSI rates.

In the present pilot study, the five SSI cases were aged between 51-60 years while six SSI cases of routine care group were aged between 31-60 years. Erekson EA et al, found a nonlinear association between age and log odds of postoperative infection. ${ }^{18}$ Lake et al, studied the role of age factor in SSI by categorizing the subject in two age group of less than 80 years and more than 80 years, however in this study no statistically significant difference was found in SSI rates in these two groups. ${ }^{10}$ Result of this study are in concordance with these studies as we also did not find correlation of age and SSI.

In present study, SSI rate was $6.45 \%$ in benign cases $(2 / 31)$ as compared to $15.7 \%$ in malignant cases $(3 / 19)$. Mahdi et al, in their study found malignancy (cervical, ovarian and endometrial) to be independent risk factor for developing SSI. ${ }^{19}$ In their study seven percent of patients undergoing laparotomy for gynecological malignancy developed SSI. Despite having higher number of malignant cases in the pilot group, the SSI rate was not higher than routine care group. This indicates that bundled interventions are effective in both benign and malignant diseases.

In the present study, vertical incision was given in $74 \%$ cases of the pilot group because of higher proportion of cervical and ovarian cancer cases recruited. All 5 cases that developed SSI were operated by vertical incision giving SSI rate of $13.5 \%$ with vertical incision. The routine care cases showed an SSI rate of $8.8 \%$ with vertical incision and $18.7 \%$ with pfannensteil incision.
Thus, type of incision does not seem to be affecting incidence of SSI. This study results are in contrast to study by Soper DE et al, and Hemsell DL et al, studied difference in SSI rate between vertical and pfannenstiel incision and found that vertical incision carries an odds ratio of 10.7 for complications like infection and suprafascial wound separation when compared with pfannenstiel incision. ${ }^{6,7}$

In the present study, the incision size ranged from 10-20 $\mathrm{cm}$ with a mean incision size of $14.38 \mathrm{~cm}$. In patients who developed SSI, the mean incision size was $18.3 \mathrm{~cm}$. This suggests that mean incision size in cases developing SSI was high $(18.3 \mathrm{~cm})$ than in those without SSI. This may be due to more malignancy cases in pilot group. The review of literature does not show any study comparing the effect of size of incision on SSI incidence.

Present study showed that adherence to CDC guidelines for prevention of SSI is inadequate in routine practice and there is a wide variation in the preoperative and postoperative care in terms of type of antibiotics, duration of antibiotic and timing of dressing change. In routine cases IV antibiotics are given for 3-7 days followed by oral antibiotics for 3-7days leading to increased cost with no reduction in SSI rates.

Post-operative abdominal wound infection represents a substantial burden for both patient as well as hospital care services both in terms of increased morbidity and mortality of patient as well as increased economic costs. A reduction in SSI rate to a minimal level may have significant benefits. In an attempt to reduce SSI there has been a significant increase in duration of IV antibiotic usage post operatively also higher group of IV antibiotics are being used indiscriminately. This is a grave situation as it may lead to higher cases of emergence of antibiotic resistance.

Among the 5 cases of SSI in the pilot group, superficial SSI was documented in two cases and deep SSI in three cases. The cases with deep SSI needed resuturing and their mean duration of hospital stay was prolonged by two weeks. In the routine care group, one of the women had fever, one had induration of stitch line and four of them had discharge from stitch line. Thus, four cases had superficial SSI and two had deep SSI.

Limitation of this study was a pilot study where we have compared pilot group with routine care group in which antibiotics were given for 5-7 days in spite of that incidence of SSI is comparable in two groups not less in the routine care group.

There is need to do RCT using standardized preoperative, preoperative and postoperative practices, then the advantage of surgical closure technique by bundeled intervention will be more obvious.

Despite the limited use of antibiotics, restricted to prophylactic and up to 24 hours postoperative the 
incidence of SSI in pilot group is comparable to routine care group.

\section{CONCLUSION}

The findings of the present study suggest that sterile surgical closure technique is easy and feasible in all setups. It adds only three extra minutes to the total duration of the surgery. The SSI rate in the present study was $10 \%$ which was comparable to that of routine care cases $(12 \%)$ and to the global SSI rate $(6-11 \%)$ despite significantly short course of perioperative antibiotics.

Anemia and diabetes are the most common risk factors for developing SSI. Type of incision does affect the SSI rate. Size of incision proportionately increases SSI rate. Despite inclusion of malignancy cases in the pilot group a low SSI rate suggests the efficacy of bundled intervention in reducing risk of SSI as well as reducing need for prolonged duration of antibiotic usage in gynaecological cancer.

Funding: No funding sources Conflict of interest: None declared

Ethical approval: The study was approved by the Institutional Ethics Committee

\section{REFERENCES}

1. Mangram AJ, Horan TC, Pearson ML, Silver LC, Jarvis WR. Guideline for Prevention of Surgical Site Infection, 1999. Centers for Disease Control and Prevention (CDC) Hospital Infection Control Practices Advisory Committee. Am J Infect Control 1999;27(2):97-132.

2. Sørensen LT. Wound healing and infection in surgery. The clinical impact of smoking and smoking cessation: a systematic review and meta-analysis. Arch Surg. 2012; 147:373-83.

3. van Walraven C, Musselman R. The surgical site infection risk score (SSIRS): a model to predict the risk of surgical site infections. PLoS One. 2013;8(6):e67167.

4. Fujii T, Tsutsumi S, Matsumoto A, Fukasawa T, Tabe Y, Yajima R, et al. Thickness of subcutaneous fat as a strong risk factor for wound infections in elective colorectal surgery: impact of prediction using preoperative CT. Digest Surg. 2010;27(4):331-5.

5. Cheadle WG. Risk factors for surgical site infection. Surg Infect. 2006;7 (supplement 1):S7-S11.

6. Soper DE, Bump RC, Hurt WG. Wound infection after abdominal hysterectomy: effect of the depth of subcutaneous tissue. Am J Obstet Gynecol. 1995; 173(2):465-9.

7. Hemsell DL, Hemsell PG, Nobles B, Johnson ER, Little $\mathrm{BB}$, Heard M. Abdominal wound problems after hysterectomy with electrocautery versus scalpel subcutaneous incision. Infect Dis Obstet Gynecol. 1993;1(1):27-31.

8. Johnson MP, Kim SJ, Langstraat CL, Jain S, Habermann EB. Using bundled interventions to reduce surgical site infection after major gynecologic cancer surgery. Obstet Gynecol. 2016;127(6):1135-44.

9. Anderson DJ, Kaye KS, Classen D, Arias KM, Podgorny K, Burstin $\mathrm{H}$, et al. Strategies to prevent surgical site infections in acute care hospitals. Infect Control Hosp Epidemiol. 2008;29(suppl 1):S51-61.

10. Lake AG, McPencow AM, Dick- Biascoechea MA, Martin DK, Erekson EA. Surgical site infection after hysterectomy. Am J Obstet Gynecol. 2013;209:490.e19.

11. Young H, Berumen C, Knepper B, Miller A, Silverman $\mathrm{M}$, Gilmartin $\mathrm{H}$, et al. Statewide collaboration to evaluate the effects of blood loss and transfusion on surgical site infection after hysterectomy. Infect Control Hosp Epidemiol. 2012;33:90-3.

12. Chelmow D, Huang E, Strohbehn K. Closure of the subcutaneous dead space and wound disruption after caesarean delivery. J Matern Fetal Neonatal Med. 2002;11:403-8.

13. Naumann RW, Hauth JC, Owen J, Hodgkins PM, Lincoln T. Subcutaneous tissue approximation in relation to wound disruption after cesarean delivery in obese women. Obstet Gynecol. 1995;85:412-6.

14. Eason E, Wells G, Garber G, Hemmings R, Luskey G, Gillett P, Martin M, Vaginal antisepsis for abdominal hysterectomy study group (other members listed in the acknowledgements). Antisepsis for abdominal hysterectomy: a randomized controlled trial of povidone-iodine gel. An Inter J Obstet Gynaecol. 2004;111(7):695-9.

15. Tanner J, Norrie P, Melen K. Preoperative hair removal to reduce surgical site infection. Cochrane Database Syst Rev. 2011;(11):CD004122.

16. Uppal S, Harris J, Al-Niaimi A, Swenson CW, Pearlman M. Prophylactic antibiotic choice and risk of surgical site infection after hysterectomy. Obstet Gynecol. 2016;127:321-9.

17. Pop-Vicas A, Musuuza JS, Schmitz M, Al-Niaimi A, Safdar N. Incidence and risk factors for surgical site infection post-hysterectomy in a tertiary care center. Am J Infect Control. 2017;45(3):284-7.

18. Erekson EA, Yip SO, Ciarleglio MM, Fried TR. Postoperative complications after gynecologic surgery. Obstet Gynaecol. 2011;118:785-93.

19. Mahdi H, Gojayev A, Buechel M, Knight J, SanMarco J, Lockhart D, et al. Surgical site infection in women undergoing surgery for gynecologic cancer. Int $\mathrm{J}$ Gynecol Cancer. 2014;24:779.

Cite this article as: Nisha $\mathrm{S}$, Rai $\mathrm{S}$, Agrawal $\mathrm{S}$, Bannerjee G, Singh R. Role of "bundled intervention" in reducing surgical site infection rate in gynecologic surgeries. Int J Reprod Contracept Obstet Gynecol 2020;9:1457-62. 